\title{
DESCRIPTIONS OF FIVE NEW SPECIES OF ANOPLURA AND MALLOPHAGA.
}

\author{
By Bruce F. Cummtases, \\ British Museum (Natural History).*
}

The following systematic work was carried out in the Entomological Department of the British Museum and is based on material in the National Collection. An endeavour has been made to extend the area of the field usually covered by the systematist in his search for characters, although the author is well aware how far short of the ideal in this matter the paper falls. The species described are :-

\section{ANopluRa.}

Haematopinus taurotragi, sp. n. Linognathoides spermophili, gen. et sp. n.

\section{Maliophaga.}

Colpocephalum mjöbergi, sp. n. Goniocotes waterstoni, sp. n. Menopon robsoni, sp. n.

Haematopinus taurotragi, sp. nov. (figs. 1, 2).

In the collection of carded material mounted dry, a large series of Haematopini was found, labelled: "From the Eland, Boselaphus oreas, Knowsby Menagerie, 1857." In spite of their age and dried condition, these specimens made excellent preparations, from which the description below is drawn up.

$H$. taurotragi belongs to the "tuberculatus" group founded in 1851 by Lucas (1) $\dagger$ with the description of $\boldsymbol{H}$. tuberculatus. Subsequently, Piaget (3) described a variety of this species under the name penicillata, which, as Neumann (2) points out, is probably no other than $H$. eurysternus (Nitzsch).

Thus, starting with $\boldsymbol{H}$. tuberculatus and $\boldsymbol{H}$. eurysternus, we must include in the group the doubtful species of Rudow, $H$. punctatus (4), the perfectly distinct form, H. bufali (Geer)-the same perhaps as Gervais' H. phtiriopsis-and the new species now under consideration.

Below is a list :-

Parasite.

H. tuberculatus (Burm.).

H. eurysternus (Nitzsch).

H. bufali (Geer).

H. punctatus, (Rudow).

H. phtiriopsis (Gervais).

H. taurotragi, sp. $\mathrm{n}$.
Host.

Bos bubalus, "Bos americana,"

Camelus dromedarius (2),

"Chinese Water Buffalo" (5).

Bos taurus.

Bos caffer (2).

Bos grunniens (6).

Bos caffer (6).

Taurotragus oryx.

External Form, Male and Female.-A description of those characters only in which this species differs from $H$. tuberculatus is sufficient. In $H$. tuberculatus the sternal plate is quadrilateral, with the anterior angles projecting a little; in the

* Published by permission of the Trustees.

†For references see page 176. 
parasite from the eland the sternal plate is a sexually dimorphic character, and in the male exhibits the form illustrated in fig. $1 b$, with which may be compared the sternal plate of the female (fig. $1 c$ ).

On the male genital plate a transverse row of hairs is present, usually four in number. Midway, each lateral margin is deeply incised so that the anterior half of the plate is in part separated from the rest. Both sternal and genital plates are somewhat variable characters in the male of $H$. tuberculatis and they are by no means

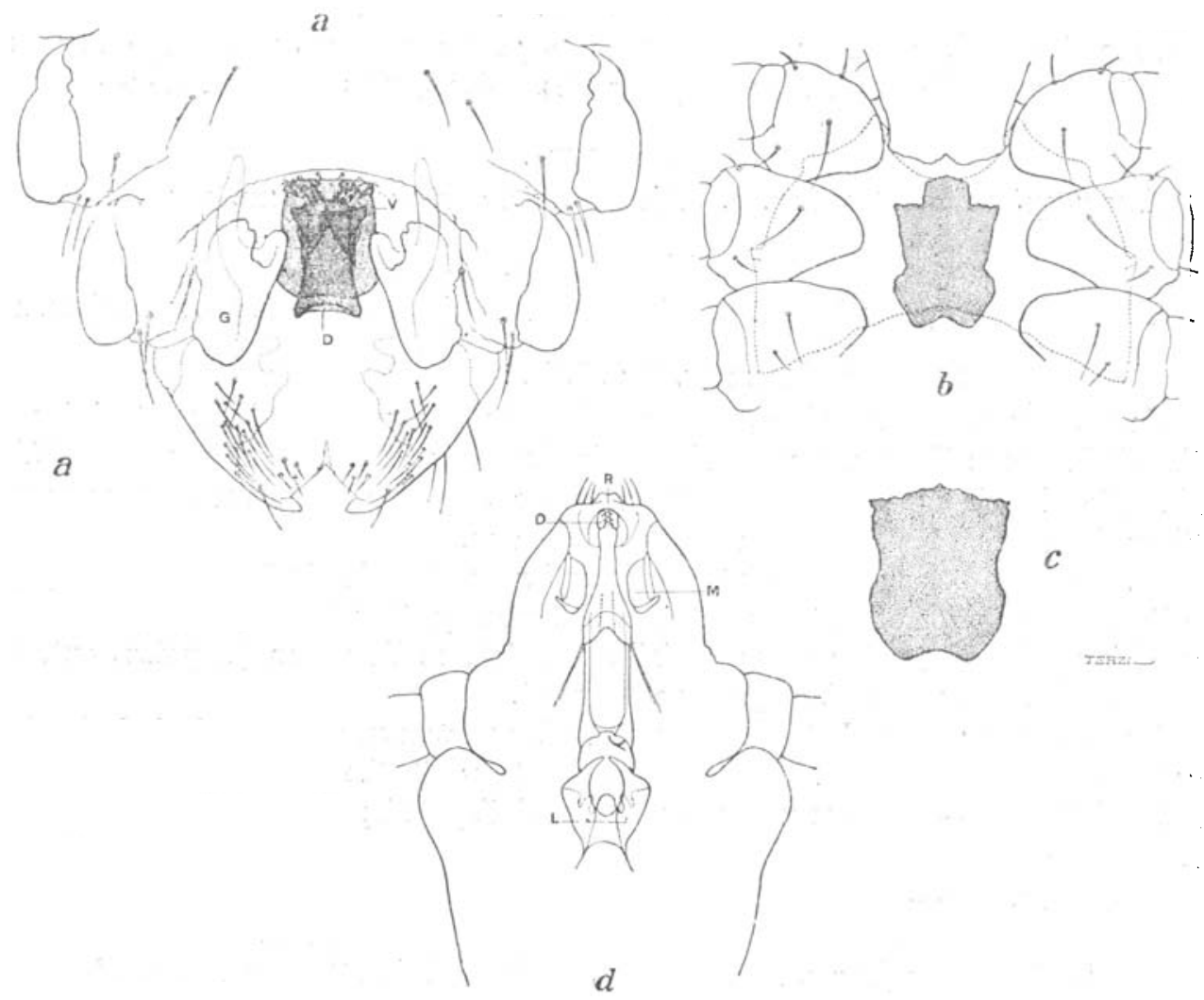

Fig. 1. Haematopinus taurotragi, sp. nov:

(a) Terminal abdominal segments of $o$, underside: D, dorsal plate: G, gonopod (the elongate hairs on the margin are omitted); $v$, ventral plate.-(b) Thoracic sternite of $z$. - (c) Thoracic sternite of.$+-(d)$ Mouth-parts: D, rostral denticles; L, larynx; $M$, mandible; $R$, rostrum; the needle-like trophi are omitted.

constant in the form now under consideration. But the male sternal plate of the one never approaches the form shown in the other, and it may be said that, as a rule, the row of hairs on the genital plate in $H$. tubercülatus consists of more than four, while the lateral incisions are less deep.

The female genital plates offer very excellent distinguishing characters. They are two in number, in the position and of the conformation indicated in the figure. In $H$. tuberculatus the ventral plate of the female is in the form of a fleur de lys. 
Chatotaxy, Male and Female-Along the temporal margin of the head are two widely spaced hairs; in $H$. tuberculatus there are 3 or 4 moderately long hairs in this position fairly close together. On the abdomen, the lower side of each pleural angle possesses 2 small hairs; in $H$. tuberculatus in the same position there is a row of 9 or 10 closely placed hairs.

Mouthparts.-In fig. $1 d$, will be found the pair of structures lying one on each side of the pharynx inside the head called by Enderlein (7) mandibles. It is not possible here to enter upon the much-discussed question of the homologies of the Anopluran

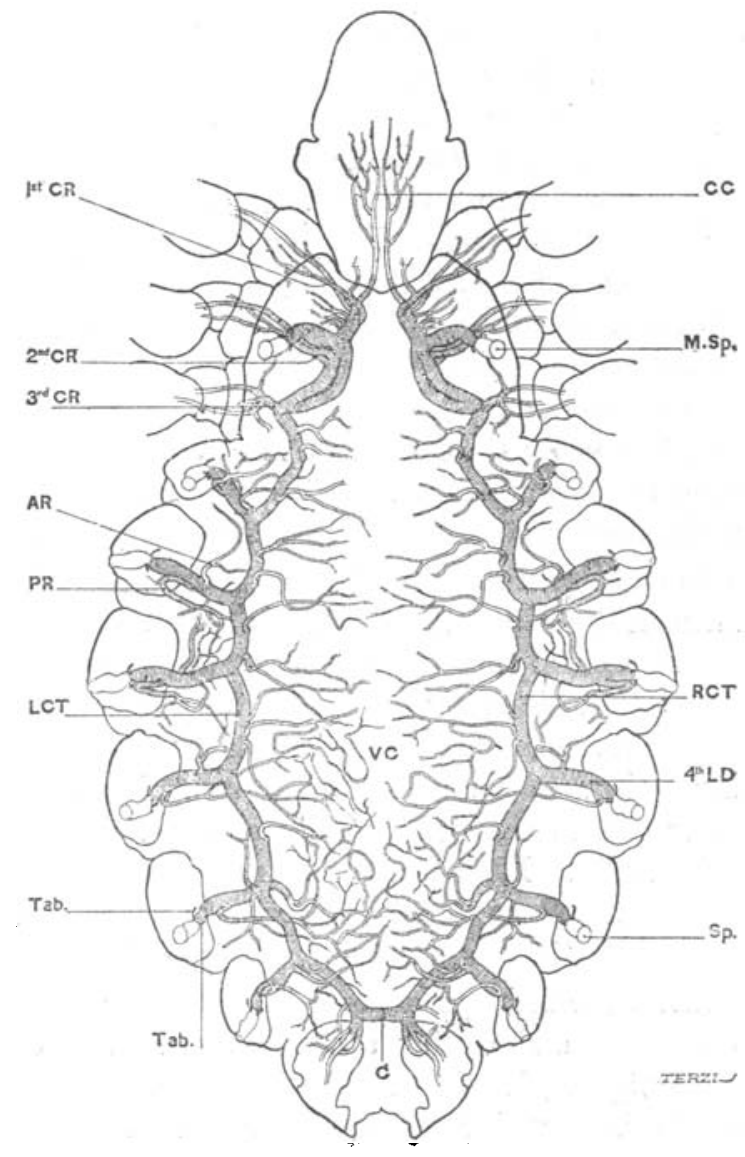

Fig. 2. Tracheal system of Haematopinus taurotragi.

AR, anterior root; C, commissüre; CC, cephalic complex; CR, crúral roots; LCT, left cardinal trunk; 4th LD, 4th lateral diverticulum; M.Sp., mesothoracio spiracle; $P R$, posterior root; RCT, right eardinal trunk; Sp., spiracle; Tab., chitinous tab of spiracle; VC, visceral complex.

mouthparts and particularly of the needle-like trophi used by these blood-sucking insects for piercing the skin. But the opportunity is taken to point out that the "mandibles" are well developed and quite visible through the integument without the aid of dissection. The chitinisation of the pharynx is very complex. The fulturae are small. 
Tracheal System (fig. 2). - The systematic value of the tracheal system will only emerge after more prolonged study. Not much is known at present about it, but in view of such information as we already have at our disposal, it is tempting to hazard the opinion that well marked generic, if not specific, characters will be found, and that in the ultimate classification of these insects this important system, together with the others, will be drawn upon to give at least its tittle of evidence in the difficult questions of phylogenetic affinity.

In $H$. taurotrag $i$ the system consists of two cardinal trunks situated longitudinally one on each side, and connected by a commissure at the posterior end of the abdomen. Each cardinal trunk gives off (in the abdomen) 6 lateral diverticula running out to the spiracles. In the thorax there is one large lateral diverticulum which runs up dorsally to the single mesothoracic spiracle. This diverticulum exceeds the main trunk itself in girth. There is an enormous visceral complex formed by the ramifying branches of roots arising from the cardinal trunks. Another large complex exists in the head, formed by the cephalic branches. In the male the commissure runs across the posterior end of the abdomen, dorsal to the genitalia, just below the level where the parameres articulate with the basal plate. In the female the commissure runs across the genital plate. With the exception of the last, each lateral diverticulum of the cardinal trunk gives off two branches, one anterior and the other posterior, the latter being the larger. Other roots arising from the cardinal trunks in the abdomen are shown in fig. 2. As regards the origin of the smaller roots, the tracheal system does not show a symmetrical arrangement on each side.

In the thorax we find a large trunk given off to the third pair of legs, which divides into two and then into still smaller divisions. Two branches likewise supply the second pair of legs, but each of these arises separately. Just in front of these the large trunk to the mesothoracic spiracle is given off. A commissure accompanies the cardinal trùnk along its inner side from the base of the branch to the third pair of legs, anastomosing again with the main trunk in front, just at the point where the trunk gives off the branch to the mesothoracic spiracle. This commissure gives origin to no smaller branches. Each cardinal trunk terminates in the prothorax by trifurcating into three relatively small branches, two of which go to the first pair of legs and one to the head. Their method of origin is displayed in fig. 2.

The spiracles present some features of interest. Mjöberg $(6, p .217)$ has figured and described the spiracles and closing apparatus in several different species of Anoplura. From these figures, it will be seen that the various species differ sometimes very considerably in regard to these characters. In all of them, and in $H . t u b e r c u l a t u s$ as well, the spiracular chamber shows the same essential features, i.e., a narrow neck and a single chitinous "tab" standing off from the neck and giving attachment to the muscle of the closing apparatus. But in $H$. taurotragi these "tabs" are two in number, one on each side of the neck. Each abdominal spiracle opens at the extreme lateral margin of each segment. The somewhat concave pleural plate lies on the ventral surface of the pleural area and the spiracular chamber lies in this concavity and can be seen from above through the transparent dorsal integument.

Male Copulatory Apparatus.-This agrees closely with the figure given by Mjöberg $(6$, p. 231) for Haematopinus phtiriopsis. That is to say, the parameres are united 
at their distal ends and the chitinisation of the preputial sac is markedly asymmetrical, particularly at the junction with the basal plate. The chitinous "leiste," marked " $\mathrm{X}$ " in Mjöberg's figure of $H$. phtiriopsis, in $H$. taurotragi curls round the ends of the parameres and extends partly up the other side of the preputial sac. There is no penis.

Measurements of HaEMatopinUs TAUROTRagi in millimetres.

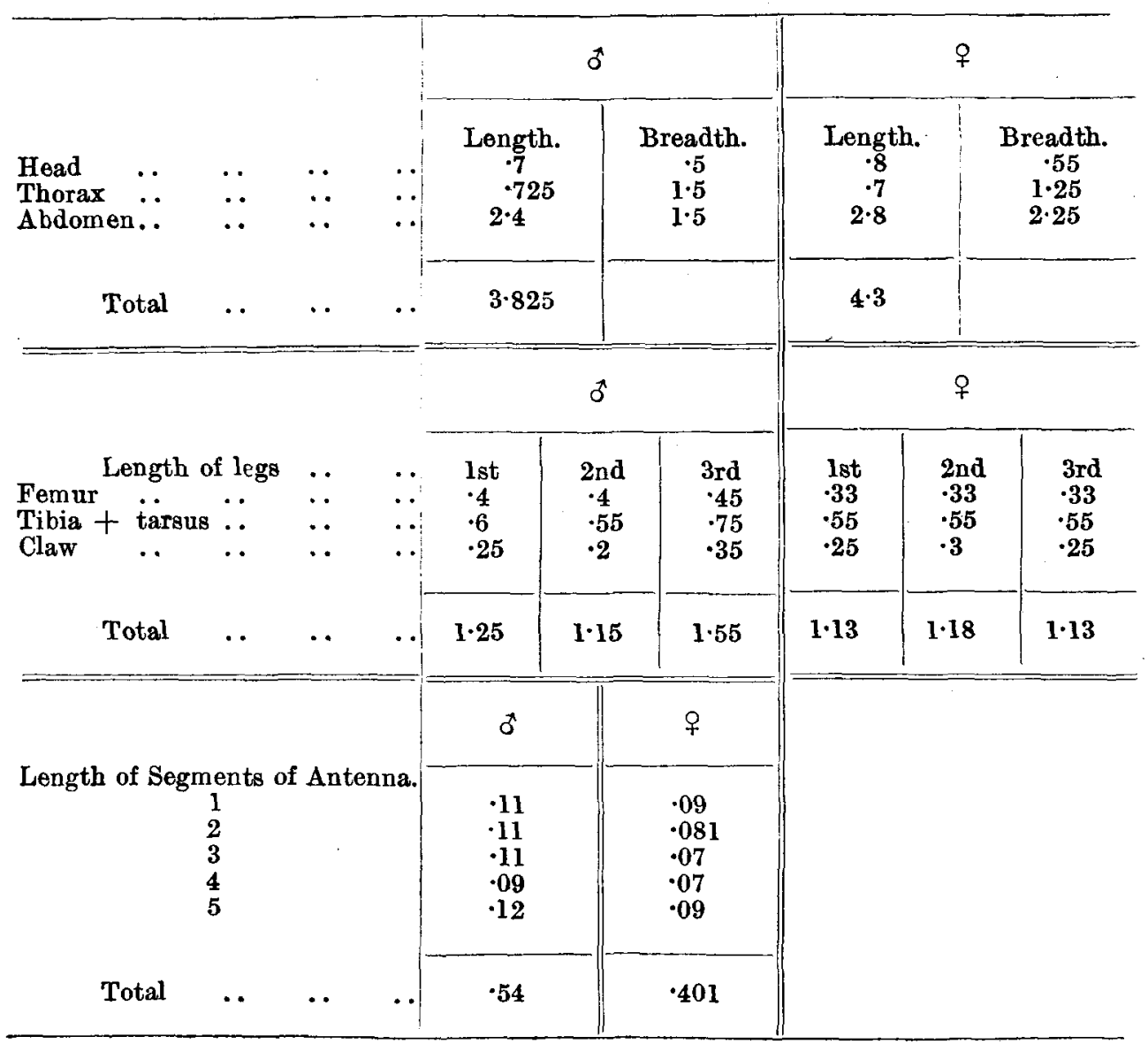

\section{Linognathoides, gen. nov.}

This new genus is instituted to include specimens of a new form of louse presented to the British Museum by the Hon. N. Charles Rothschild and collected in Transcaspia by W. Koshantchikov on two different hosts, viz., Cricetus phaeus, now known as Cricetulus phaeus (Pallas), belonging to the subfamily Cricetinae, family Muridae, and Spermophilus leptodactylus, now known as Citellus leptodactylus (Licht.), belonging to the subfamily Sciurinae, family Sciuridae.

The Museum collection contains a second species of Linognathoides, also the gift of Mr. Rothschild, which stands very near the present species and was taken on Marmota pruinosus, Gmelin, a North American squirrel of the subfamily Sciurinae. 
This second species is probably new, but is represented by only two poor specimens: The fact that they stand so near to the species about to be described affords strong presumptive evidence that the real host of $L$. spermophili is Spermophilis (or Citellus) and not the Murid Cricetulus. A reference to the published deseriptions of species from squirrels, e.g., Piaget's Haematopinus setosus from Xerus guttulus and Polyplax (?) montana (Osborn) from Sciurus cinereus, makes it probable that at least a few of these will be found to fall very naturally into the new genus.

Linognathoides occupies a position midway between the genera Linognathus and Polyplax. The Polyplax characters are the strongly chitinised abdominal pleurites, which project on each side from the sides of the abdomen as blunt teeth, and the small size of the spiracles. The Linognathus characters are the large, soft abdomen - without tergites or sternites, fat and much distended (so that it is difficult to clear with potash), and the long hairs which clothe it dorsally and ventrally. Other generic characters may be taken from the head; which widens suddenly behind the antennae, the sexual dimorphism present in the latter, and the terminal segment of the abdomen of the male, which is drawn out on each side (fig. 3 ) into a fingershaped lobe, exactly as in Piaget's figure of $\boldsymbol{H}$. setosus.

Linognathoides spermophili, sp. nov. (fig. 3).

External Form, Male.-Head: The first segment of the antennae is the broadest, and at its distal end on the upper surface is a minute, short denticle or "thorn." There is another denticle at the distal anterior angle of the third segment. The third segment differs from that of the female in that the distal anterior angle projects somewhat and the anterior lateral margin is consequently longer than the posterior. Thorax broadening posteriorly. No sternal plates visible. First pair of legs with the claw bifid at the tip; coxae of all three pairs widely separated, but those of the first pair nearer to each other than those of the other two pairs. Abdomen: The end of the abdomen is dorsally produced into a rectangular flap (fig. 3) formed by the tergite of the terminal segment. On each side of this flap the pleurae are produced into two finger-shaped processes, one on each side, converging inwards and meeting each other at the tip. On the ventral side a membrane stretches across between these two processes. From the base of each process a splint-like piece of chitin runs forward on the ventral surface to meet the genital plate, which is of the form shewn in the figure.

External Form, Female--Head: The pre-antennal area is longer than it is in the male ; the denticles are absent from the antennae, and the third segment of the latter is of the same form as the second. Abdomen as in the male, the sutures between the segments are difficult to see, and the tergites and sternites are absent. It is rather more swollen, soft and ovate than in the male. The pleurites do not differ in shape from those of the male (fig. 3). The gonopods are triangular, the apex of each triangle pointing inwards. Between the gonopods is a triangular genital plate, with the apex pointing backwards. In front of this plate is a second one, transverse in position and broader than long.

Chaetotaxy and Colouration, Male.-Head: On the margin of the pre-antennal area two small hairs, one on each side of the oral cone. A longer one on each side, a little further back; near the latter, but just inside the margin, another hair: 
On the dorsal surface on the pre-antennal area, just behind the posterior margin of the transverse brown band, two small hairs in the middle, fairly close together. A little further back two more small hairs, widely separated. Behind the antennae two longer hairs one on each side, well within the lateral border near the ocular emargination. Two or three small hairs in the ocular emargination. Further back on the temporal wings, three hairs and one long bristle. In the middle of the dorsal surface of the past-antennal area, two minute hairs. On the ventral surface two small hairs one on each side of the rostrum. A hair of medium length on each side on the lateral margin of the head, just inside the posterior margin of the first segment of the antenna. Thorax: On the
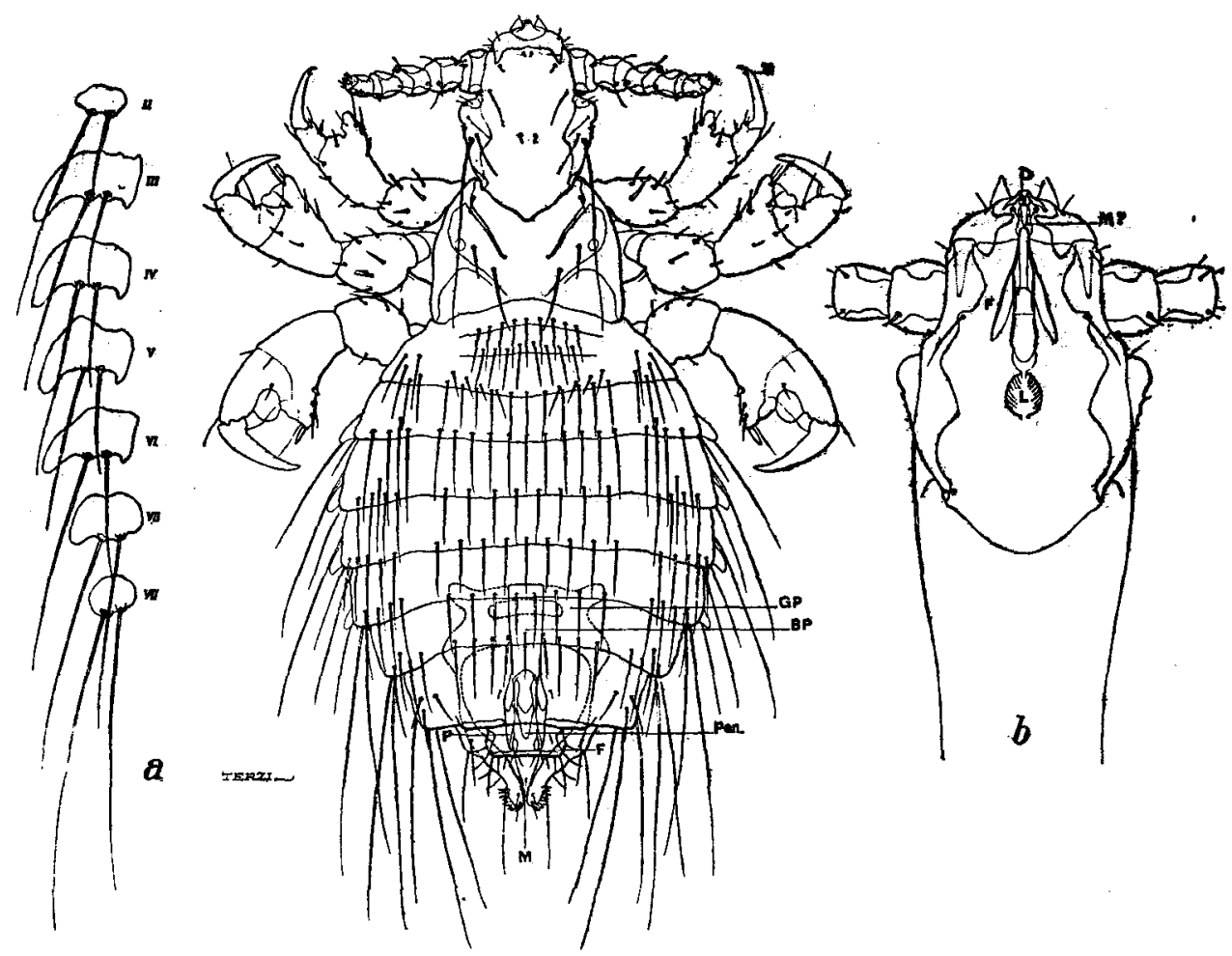

Fig. 3. Linognathoides spermophili, sp. nov., $\hat{0}$ : $a$, bifid claw; BP, basal plate; GP, genital plate; $F$, flap; $M$, mesosome; $P$, parameron; Pen., penis.-(a) Abdominal pleurites dissected off.- (b) Mouth-parts : D, rostral denticles; F, fultura; L, larynx; M (?), mandibles.

mesonotum just inside the spiracle, one short hair and one long bristle. Abdomen : On the dorsal surface, segment 1 with numerous hairs in the middle; segments 2 to 8 with a row of well-spaced hairs; segment 8 bare, excepting for two short hairs in the middle. The rectangular flap of the terminal segment possesses several hairs along the margin. Between the hairs above described occupying the mid-dorsal region and the hairs on the pleural area, there is in each segment a break or bare patch, which results in a longitudinal bare patch down each lateral part of the dorsal surface. 
On the margin of each pleural plate are two long hairs (fig. $3 a$ ). On the dorsal side, in the pleural area of segment 2, is an irregular patch of short hairs; on segment 3 a row of three long hairs with a fourth behind ; on segment $4 \mathrm{a}$ row of four long hairs and one behind ; on segment 5, of five long hairs ; on segment 6, of four long hairs ; on segment 7 there is a row of three long hairs and one behind; and on segment 8 three short hairs irregularly placed. The termination of each of the two finger-shaped processes at the end of the abdomen is armed with a number of strong recurved denticles. On the ventral surface there is a single row of hairs on each segment, excepting segment 8 , which has only two hairs, one on each side of the basal plate. Further down are two more hairs, one on each side of the elongate mesosome of the copulatory apparatus.

On the head there are two brown "taches" in front of the antennae, one on each side, and there is a small brown mark in each ocular emargination.

Chaetotaxy, Female.-Abdomen with two longitudinal bare areas as in the male. Segment 9 is bare on the dorsal surface, except for four hairs on each side in a short transverse row, situated along the lower margin of the extreme lateral portions of the terminal dark band. On the ventral surface the hairs, as in the male, are less numerous than they are on the dorsal surface, and thinner, shorter and more widely spaced. They are arranged (somewhat irregularly) in two rows on each segment, excepting on segments 8 and 9 , the former having a batch of minute hairs on the genital plate, and the latter with the hairs arranged on the gonopods and genital plate as described immediately below, i.e., there is a group of four hairs of medium length on the lower part of each gonopod and two smaller ones on the inside of these. Over the triangular genital plate there is a patch of 10 minute hairs arising from large alveoli. There is a powerful spine on each side of the genital opening, standing in a group of smaller hairs. A short longitudinal row of hairs runs from the base of each gonopod backwards, passing outside the spine to the margin.

On the dorsal surface of the last abdominal segment, a narrow band of dark-coloured chitin runs in a semi-circular fashion from one lateral margin to the other. The concave side of the band is posterior, and the two lateral ends on reaching the pleurae double back beneath to the ventral side, where they carry the large spine and group of hairs which guard the opening to the genital organs.

Mouth-parts.-Mandibles of the shape and in the position of those figured for Haematopinus taurotragi are absent. Enderlein (7) in his description of the mouthparts of Pediculus vestimenti regards the lateral "taches" as containing the vestigial remains of the mandibles, which are so well developed apparently throughout the genus Haematopinus. These " taches," however, appear to be no more than coloured and strongly chitinised supports for the sides of the proboscis, and resemble similar chitinous thickenings on the ocular emarginations and on the temples and elsewhere. I have tentatively suggested in fig $3 b$, that the two small pieces one on each side of the oesophagus in front may be homologous with the mandibles. The larynx is quite characteristic of this species, being transversely furrowed and roughly heart-shaped.

Male Copulatory Apparatus*-The paramera are so closely applied to the mesosome

* The terminology adopted in this and other descriptions of the copulatory apparatus of the male is that suggested by the Rev. James Waterston (8). 
as to be scarcely distinguishable from it. The endomera are fused and drawn out into a structure shaped like the head of a spear with serrate lateral margins. The penis is present. The basal plate is long and parallel-sided.

Measurements of LINOGNATHOIDES SPERMOPHIII in millimetres.

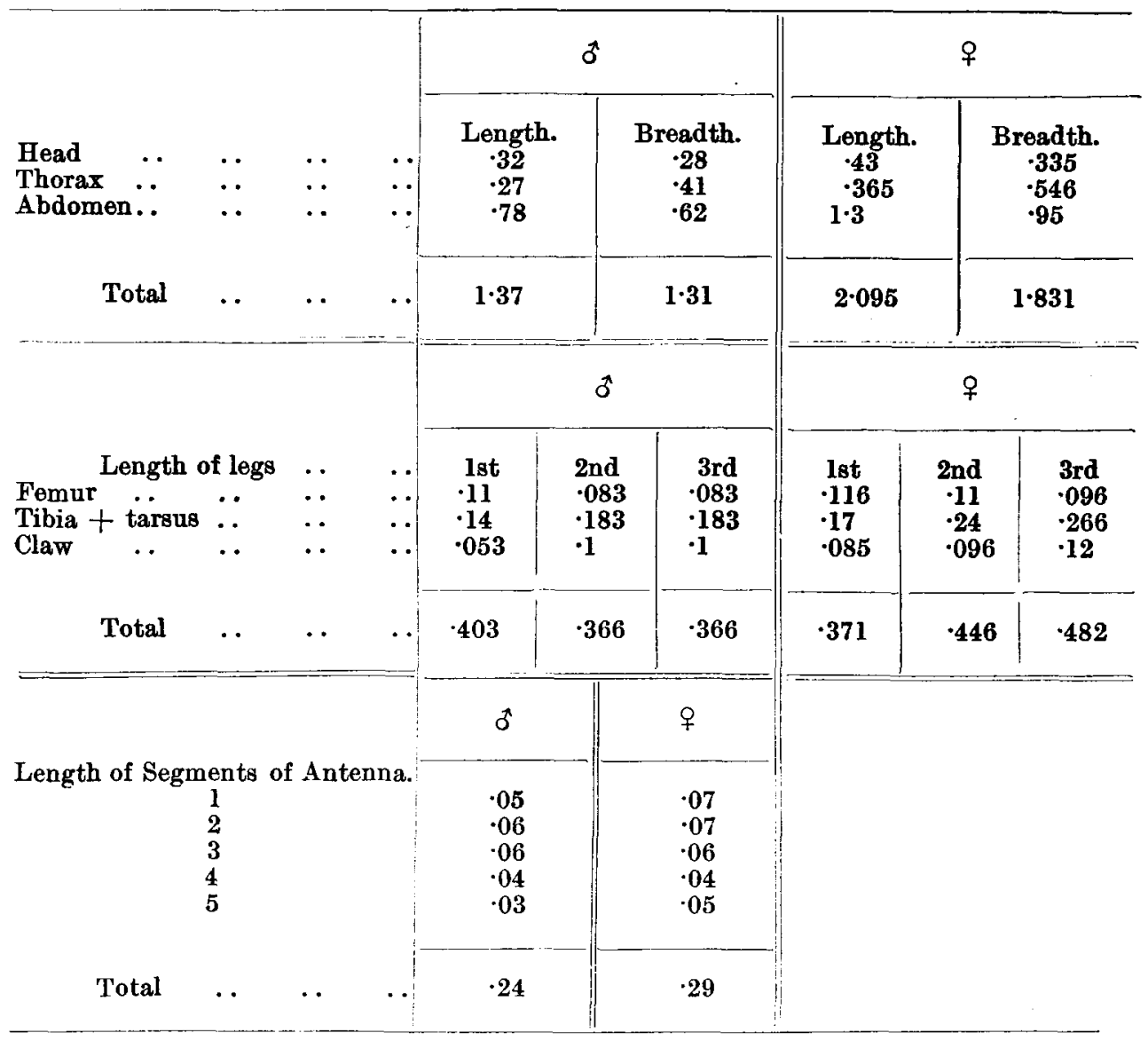

Colpocephalum mjöbergi, sp. nov. (figs. $4,5,6$ ).

The species of Colpocephalum here described was taken on a species of crested guineafowl, Guttera cristata, Pallas, in the Budongo Forest, Unyoro, Uganda, on 14th December 1911, being part of material submitted for determination and kindly presented to the Museum by the Imperial Bureau of Entomology.

External Form, Male (fig. 4).-Head: The eye is prominent and the cornea apparently consists of two lenses connected by a neck. The black pigment of the eye is broad at the base, the distal half being conical, the cone running out to touch the cornea at the neck between the two lenses. The antennae have the third segment pedunculate and the fourth broad, columnar and parallel-sided. Thorax: The prosternite is small, oval. The endoskeleton is worth remark. The "clavicles" are strong bars running upwards and forwards from each side of the prosternite (C 53) 
to be inserted into the rounded anterior corner, just above the angle made by the transverse band where it enters the longitudinal band on each side. The upper end of each clavicle is a little swollen and shows as a minute colourless circle upon the dorsal integument, suggesting that this may be an atrophied spiracle and the clavicle itself a tracheal tube metamorphosed into a chitinous support. Legs : First pair : the coxae lie longitudinally and are in shape something like a propeller-blade; posterior margin of the femur very convex. Second pair: coxa in the form of a truncated cone; femur less powerful. In all three pairs of legs at the distal extremity of the
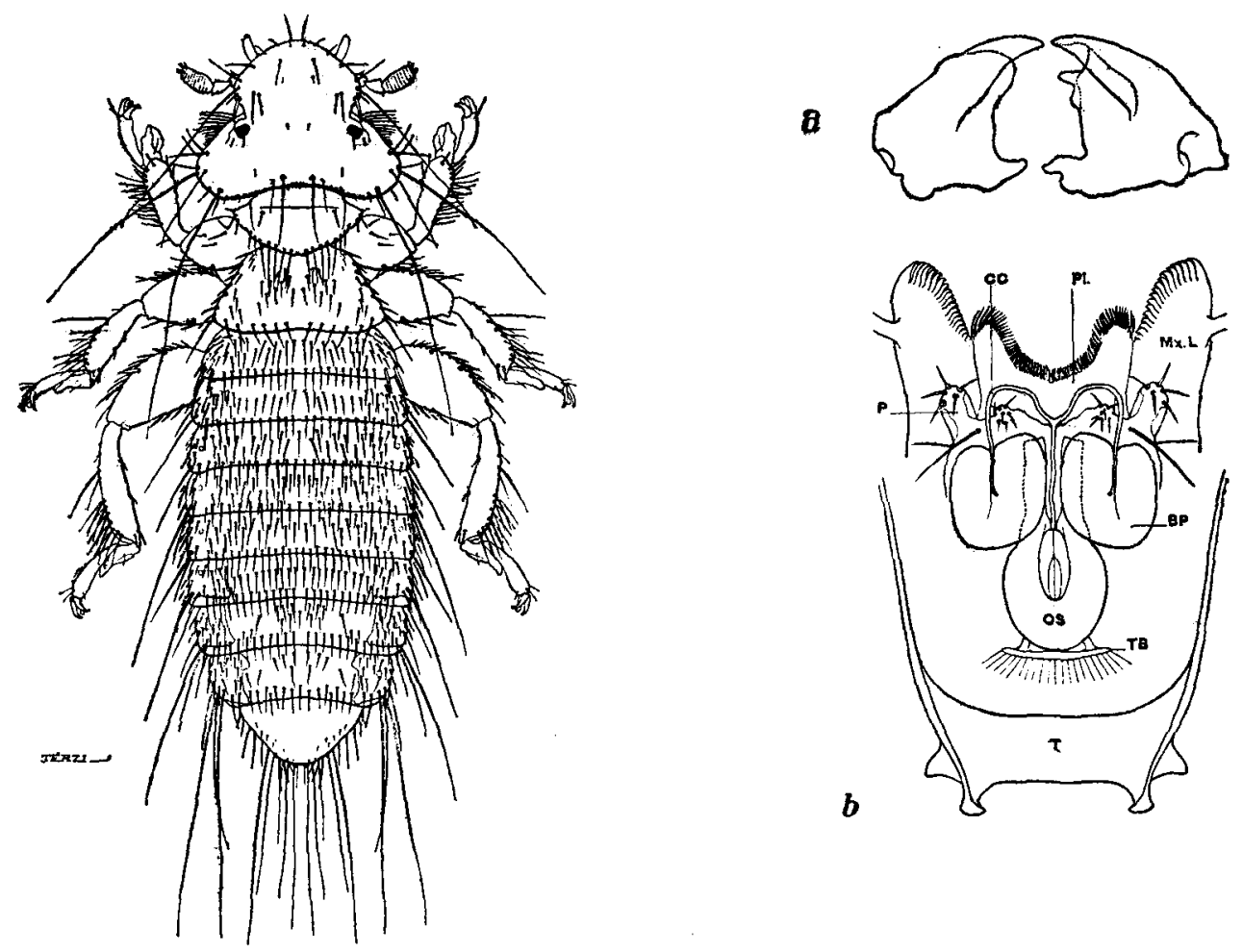

Fig. 4. Colpocephalum $\overline{\mathbf{\lambda} m j o ̈ b e r g i, ~ s p . ~ n o v ., ~} 0$.

(a) Mandibles.-(b) Mouth-parts, with the mandibles removed: BP, basal piece; CC, chitinous chords; Mx.L, maxillary lobe; OS, oesophageal sclerite; P, labial palpus; PI., fringed plate; T, tentorium; TB, transverse bar, with muscle strands attached.

tarsus, projecting between the two claws, in the position usually occupied by the pulvillus in Diptera, are two minute delicate organs (fig.5, $\mathrm{Pr}$.). Only one on each tarsus is shown in the illustration. These small pulvillus-like structures occur in Menopon and other genera and are perhaps of general occurrence in the Mallophaga. Kellogg and Nakayama (9) have recently described them in their new genus Philandesia. If they really prove to be homologous with the pulvillus, the Mallophagan onychium must be something sui generis. Abdomen: The figure (fig. 4) gives an excellent idea of the shape. 
External Form, Female (fig. 5).-Abdomen: The genital plate is triangular, with the apex pointing backwards. There is another plate of indistinct outline in front of it and covered with a dense cluster of hairs. On each side of the genital plate a

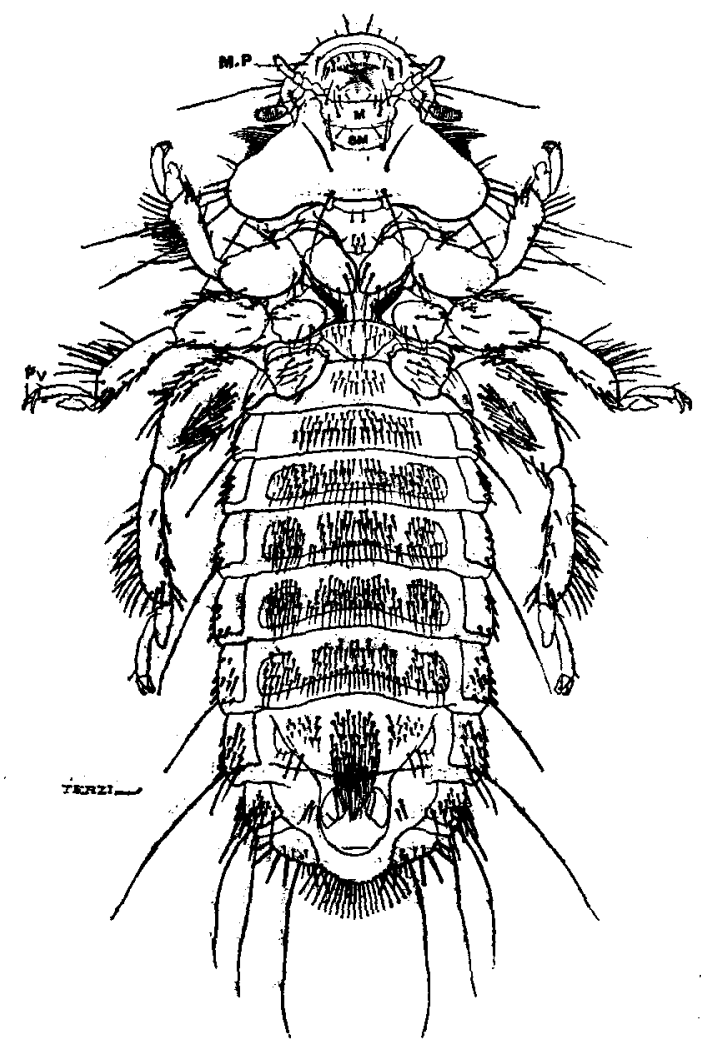

Fig. 5. Colpocephalum mjöbergi, sp. nov., i, underside: $M$, mentum; MP, maxillary palpus; Pv, pulvillus; SM, submentum.

small somewhat triangular plate is situated, of rather uncertain outline. The whole abdomen is broader than that of the male and less graduated in width towards the tip, which is quite as wide as the base.

Chaetotaxy, Male (fig. 4).-Head: On the anterior margin two fairly long hairs; widely separated; two shorter ones, one on each side, further back. On the prominence in front of the ocular emargination are situated one long bristle, two shorter spiny ones behind it, and one in front of it. At about the same level, only inside the margin, on the dorsal surface, two hairs of medium length, close together. On the margin at the base of the clypeal area and at about the level of the mandibles, a fairly long hair on each side. A short hair over the eye. A strong ocular fringe is present, the anterior hairs being the longest. On the temples, on each side, two very elongate hairs and two or three shorter ones. Along the occipital line, four hairs of medium length, overhanging the pronotum. Further out, near the temporal 
angles, two widely-spaced minute hairs. On the ventral surface, two longitudinal rows of hairs, four or five in each row, running from the submentum to the occiput. On the premandibular cushion there are 12 spines on the anterior margin, the outside ones being the longest, and 16 smaller ones, more closely spaced but with larger alveoli, on the posterior margin. Just behind the posterior margin of the cushion and near the tips of the mandibles are two small denticles, each of them bifid. Thorax : Anterior margin of pronotum with a small hair, just outside the occipital hole. The angles of the lateral wings each with two short spines, one below the other; two more behind, one below the other. The posterior margin of the pronotum with a row of well-spaced hairs of medium length. Just inside the wing, at each end of the transverse line, a small hair. Lateral margins of the metanotum with many short hairs. Other hairs arranged as in the figure. The legs are noticeable for a patch of thick hairs on the lower surface of the hind femur. Abdomen: Tergites each with two irregular rows of well-spaced hairs of medium length, except the ninth, which is bare. Pleurae with longer hairs, one being, as a rule, much longer than the rest. Pleurae of segment 8 with two long hairs. The lateral margins of the terminal segment with six hairs on each side, the last one being very long; the apical margin with eight or nine smaller hairs. Sternites 3 to 7 with a patch of short hairs crowded together on each side of the middle line, well within the lateral margin. Sternites 2 and 3 with a number of fairly small, irregularly arranged hairs, present also on the other sternites, between the right and left patches. Lower lip of the opening to the genital chamber with numerous long bristles.

Chaetotaxy, Female (fig. 5).-Abdomen: Tergites bare except those of segments 8 and 9 , on the former of which there is a row of hairs on the posterior margin, and on the latter, numerous small somewhat scattered hairs arranged in an irregular row. Sternites as in the male. Genital plate bare, but covered by the cluster of hairs which are situated on the plate in front of it. Integument dorsally and ventrally covered with an immense number of minute denticles, like the skin of a dogfish. Pleurae with many short spines. Pleurae of segments 2, 4,6 and 7 each with a single long hair, 8 with two long hairs. Terminal margin of the abdomen with four powerful spines on each side and one long hair on the inside of these ; between these two longer hairs are numerous less powerful spines. Lip of the opening to the genital chamber closely set with numerous spiny hairs.

Colouration.-Both sexes are white above; eyes black. On the ventral surface the male has the sternites of the thorax dark brown or black. The abdominal sternites also show in most specimens an irregular, dark brown patch on each side. The ventral surface of the female is coloured as follows:-Tips of mandibles black; two black marks on each side of the occiput ; prosternite brown, lateral bands in the mesosternal region black; abdominal pleurae each with a heavy, dark brown, longitudinal band ; each sternite banded transversely with brown, paler in the middle.

Mouth-parts (fig. 4, a, b).-Labium: The submentum is a well-marked broad rectangular plate. The mentum carries two small lobes, usually called paraglossae. Between these are two slight projections carrying several small hairs. Isopogometric apparatus*: The anterior cornua of the oesophageal sclerite (or lyriform organ),

* See E. Armenante (10). 
are rather long and truncate at the tips. There are no posterior cornua, but, at the posterior end of the sclerite, is a transverse chitinous bar (fig. 4, $b$, TB) which projects on each side, each free end being buttressed against the oesophageal sclerite by a small piece which runs forward and somewhat downwards, as the bar is not only posterior to the sclerite, but also dorsal. Numerous muscle fibres are attached to the transverse bar. The two basal pieces (or lingual " glands") are parallel-sided, with truncate anterior and posterior ends. The chitinous chord (or "duct") bifurcates far forward, where each ramus or branch curves round and runs backward to enter the basal piece. The descending and ascending chords are parallel to each other. In front, at the point of bifurcation, the chords bear a delicate plate, the dentate anterior edge of which projects from the mouth. First maxillae: The palpus is fairly long. The first segment is wider distally than proximally, the two middle segments about equal in size, and the terminal segment longest and columnar. The lobe is rather elongate and narrow. In front, it is, as usual, armed with a patch of minute hook-shaped denticles. The lobe is thinly chitinised, except on the outer margin behind the patch of hooks, where there is a thickening, for a muscle attachment. Mandibles as usual. In optical section a series of deep, longitudinal grooves are seen to be present. Cushion much broader than long, considerably shorter than the cushion of the Goniodidae. It is convex in front, and slightly concave behind, the thickened margin being continuous all the way around. In the Goniodidae it ceases at the base on each side and the lower margin is therefore separate, at each end supported by a narrow longitudinal sclerite which runs backward beneath the mandibles. Tentorium: I have ventured to homologise with the tentorium a structure of the head, which I do not think has hitherto been described in Mallophaga. This is a broad band-like transverse plate situated in the gular region just below the integument. The posterior lateral angles project backwards in a well marked process (fig. $4, b, \mathrm{~T}$ ). At each side the band curves upwards to the roof of the skull. The perpendicular walls thus formed run forward towards the mouth-parts, joining up with the thick chitin which forms the point of articulation to the mandibles.

Alimentary Canal (fig. 6, a).-This is of the same general type, which distinguishes the Amblycera, but the crop, or ingluvies, is unusually large and without anterior diverticula. Its large size and perfect oval shape recalls the crop in the Ischnocera. The lining is covered with very minute hairs, and around the lower end of the crop is the usual row of teeth (10) or ingluvial comb (fig. 6, $a, \mathrm{CT}$ ). Each tooth is a flat sabre-like blade, serrate along one edge. The ventriculus, in the specimens examined (which were not very well preserved for the study of the soft parts), is a somewhat broad tube without anterior diverticula and connected with the crop by no very marked constriction. The rectum is large and globular, or bowl-shaped. The six glandular patches are rectangular with rounded angles.

Male Reproductive Organs (fig. 6, c).-As usual in the Amblycera, there are six testes, three on each side, pear-shaped and sessile on the vas deferens. The vesicula seminalis bears a curious resemblance to the Ctenophor, Hormiphora (fig. 6, c, vs). The originally double character of this organ is still indicated by a fine line (or furrow) which runs up through the aboral or anterior end. Two accessory glands are present, one on each side of the base of the vesicula seminalis. They are attached lower down and nearer the upper end of the ductus ejaculatorius than an examination of 
the figure might lead one to suppose. Accompanying the ductus from the seminal vesicle towards the preputial sac are two enigmatic structures, one on each side. The preputial sac is large when expanded, its surface covered with minute recurved denticles.

Male Copulatory Apparatus (fig. 6, b).-The basal plate is elongate, the strongly chitinised lateral margins curving in towards each other. The paramera are long and curve gracefully outwards at the tip. The articulation of the paramera with the
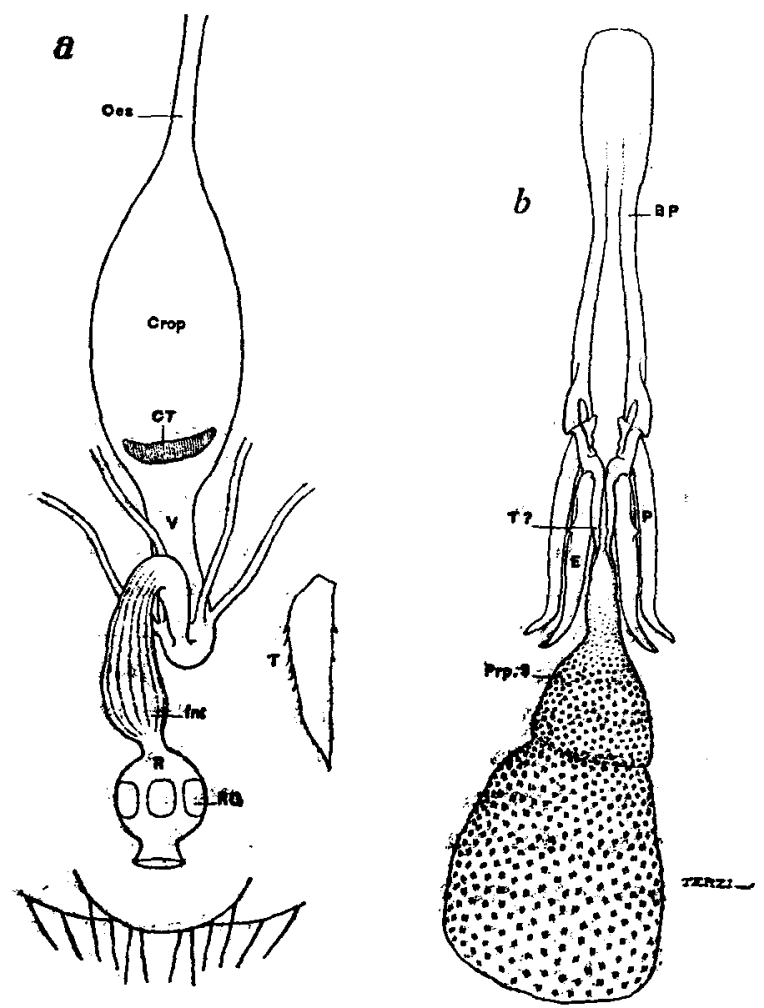

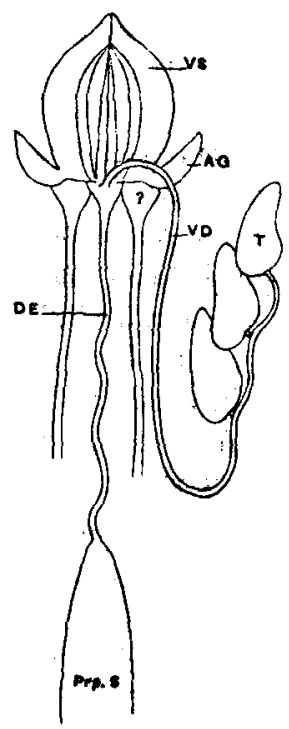

c

Fig. 6. Colpocephalum mjöbergi, sp. nov.

(a) Alimentary canal of $q$; Oes., oesophagus; $C T$, crop teeth; $V$, ventriculus ; Int. intestine; $R$, rectum; $R G$, rectal glands; $T$, one of the crop teoth highly magnified.(b) Male copulatory apparatus: BP, basal plate; $E$, endomeron; $P$, parameron; $T$, telomeron; Prp. S, preputial sac.-(c) Internal genital organs of ; : VS, vesicula seminalis; AG, accessory gland; VD, vas deferens; T, testis; DE, ductus ejaculatorias; Prp. 5, preputial sac.

basal plate is somewhat complex (fig. 6, $b, \mathrm{P}$ ). Each of the side-pieces (or lateral margins) of the basal-plate sends forward beneath the articulation of each parameron a narrower piece which, meeting its fellow in the middle line, runs forward with it without fusing to the base of the preputial sac, a deep groove lying between them ; they perhaps represent the telomera. Distally they fade away into the membrane of the sac. The endomera are well developed, resembling the paramera in form, and are articulated below the latter to the basal plate. 
FIVE NEW SPECIES OF ANOPLURA AND MALLOPHAGA.

Heasurements of COLPOCEPHALUM MJÖBERGI in millimetres.

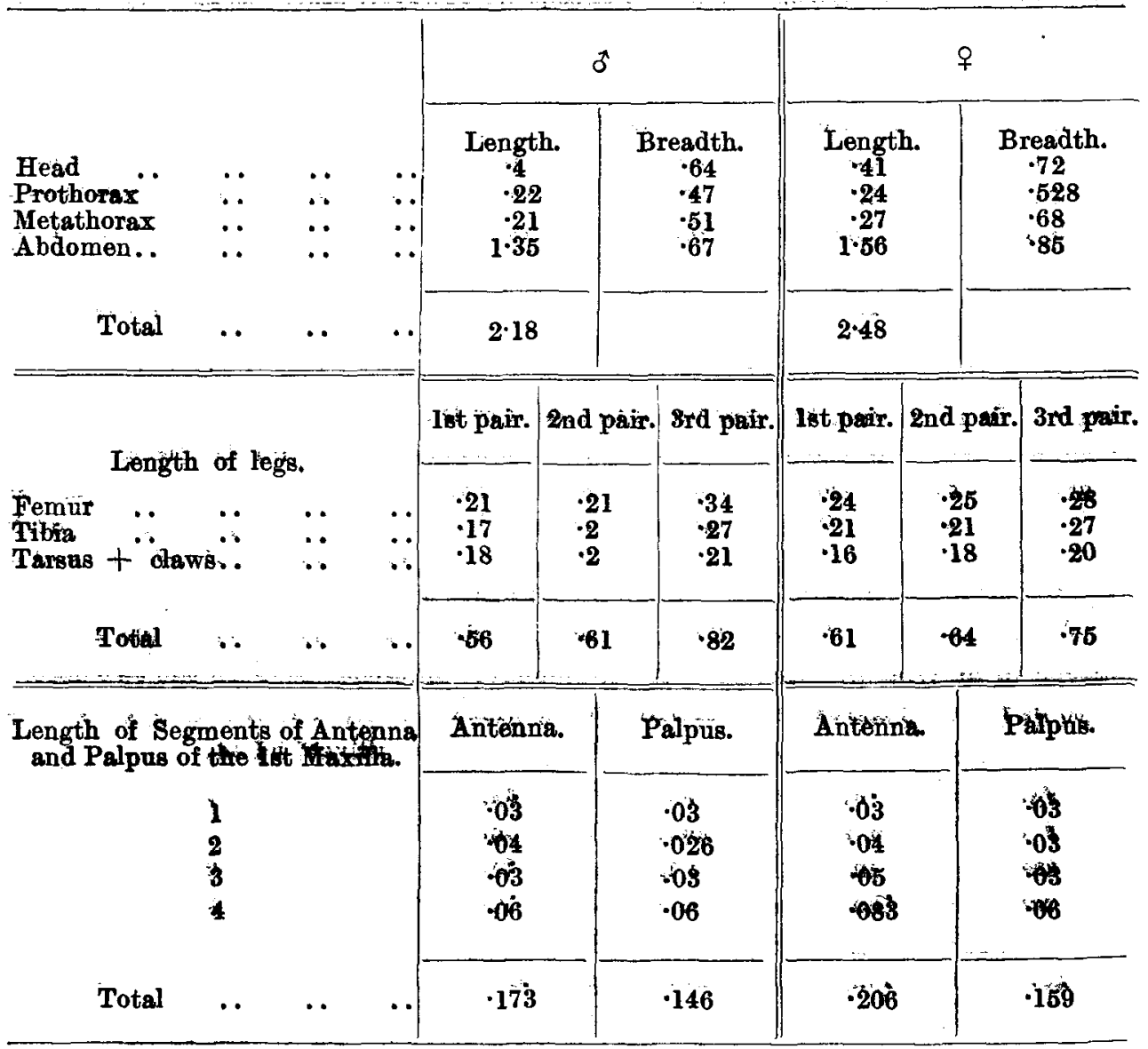

Wenopon robseni, sp. nov. (fig. 7).

This remarkable louse, named after Mr. G. C. Robson, of the Zoological Department of the British Museum, was brought back by the Wollaston Expedition to Dutch New Guinea, 1913. The label on the tube endorsed "C. B. K." (C. Boden Kloss) conveyed the information that its contents, including 2 females of the new Menopon, several specimens of Nirmus varius and a single Corvine Dochophorus, were taken at Launch Camp, Setakwa River, on 13th March 1913, on the "Hawk Crow." Mr. A. F. R. Wollaston kindly tells me that I should be probably correct in referring this to Gymnocorax senex (Corvidae).

$M$. robsoni belongs to the general type of Carriker's Colpocephalum extraneum from the nightjar, Nyctidromus albicollis (Costa Rica) (11) and also of Kellogg's Colpocephalum sjöstedti from Corvus scapulatus and Corvultur albicollis (Africa) (12), characterised by the development of pro- meso- and meta-thorax into separate thoracic elements (as in Trinoton). There can be no doubt that these two species, together with the new $M$. robsoni, which are all closely related, form the nucleus of a new genus of Mallophaga, with members of the Corvidae as hosts. 
The genus, Colpocephalum, is in the present state of our knowledge, often difficult to separate from Menopon. The new species is, however, placed in Menopon, rather than in Colpocephalum, on account of the characteristic Menopoid roofing over of the ocular emargination.

I have been unable to refer to Carriker's description of $C$. extraneum but am satisfied from Kellogg's references to it that $M$. robsoni is a different species. To $C$. sjöstedti the new species stands very close. Fortunately, the British Museum possesses a single female specimen of $C$. sjöstedti identified by Prof. Kellogg, and by the aid of this and his figure and description it has been possible to signal the differences. It was sometimes difficult to make the figure agree with the description, and the specimen of $C$. sjöstedti is unfortunately a poor mount. But according to the figure and the specimen the mesonotum of that species runs out straight into a pointed posterior angle. In $M$. robsoni the outline at the sides of the mesonotum is convex. In the abdomen, segments 2 to 6 in $C$. sjöstedti have many short spines on the lateral margins, segments 7 to the last each having two elongate hairs in the same position. In $M$. robsoni segment 2 also has two elongate hairs. The pleural plates are quite different in form in the two species; there are no median plates in $M$. robsoni, and in C. sjöstedti on the dorsal surface just inside the pleural region of the abdomen on each of the segments $2,3,4,6$ and 8 there is on each side a single elongate bristle which is absent in $M$. robsoni. Another very considerable difference between the two species is to be found in the sternites of the thorax, which are different in form (particularly the metasternum), and the chaetotaxy is on an entirely different plan.

External Form, Female.-General conformation peculiar. The thorax dorso-ventrally is deep and antero-posteriorly very long. The abdomen is very short and decreases rapidly in depth from the base to the apex. Head: The figure gives an accurate idea of the shape of the head, and a reference to it (fig. 7) and to the figure of the antenna (fig. $7, b$ ) makes further details superfluous. Thorax: Wings of pronotum rectangular. Posterior margin convex on the mesonotum and rounded. Prosternite like a bow and arrow, the tip of the arrow pointing to the rear and projecting slightly beyond the convex margin of the plate, this margin being semicircular and representing the bow. The anterior part of the prosternite, representing the posterior part of the arrow, instead of being narrow is broad. The clavicles run down from the anterior shoulders to join the posterior part of the prosternite. The mesosternite is a powerful sclerite, densely chitinous and roughly quadrilateral. The four angles each with a chitinous ray. The two anterior rays are long, run outwards transversely on each side to the lateral margin and, joining the mesonotum, coil around the base of the coxa of the second pair of legs so as to form an acebabulun. The front margin of the plate is slightly convex. The hind margin is straight. The metanotum is produced on each side into two large shoulders. The metasternite is the largest of the three sternal plates; it is dagger-shaped with three acute angles anteriorly, one on each side and one in front. Legs : Coxae of first pair lying just below the prosternite and in front of the anterior bars of the mesosternite. They are nearer to each other than the other two pairs of coxae, and also longer. Abdomen: Nine segments, with traces of a tenth on the ventral side at the base. Spiracles minute, only 5 visible. Segments 8 and 9 longer than the others. Basal segments short, with the suggestion of being somewhat telescoped towards the metathorax. 
Pleurites with an oblique whitish line dorsally in segments $3,4,5$ and 6 . Ventrally, segment 1 has a short, broad sternite, divided by a median line into two separate plates. Segment 2 with a sternite longer than any except those of 8 and 9 . On segments $3,4,5,6$ and 7 there are no median sternal plates; that of 8 is large and semicircular.

Chaetotaxy, Female--Head: Two straight hairs close together on the clypeal margin in front. On the margin, in front of the spot where the tip of the maxillary palpus projects, 3 more hairs. Two hairs above the tip of the palpus. Two very long hairs and two shorter ones on the margin before the antennae. The ocular
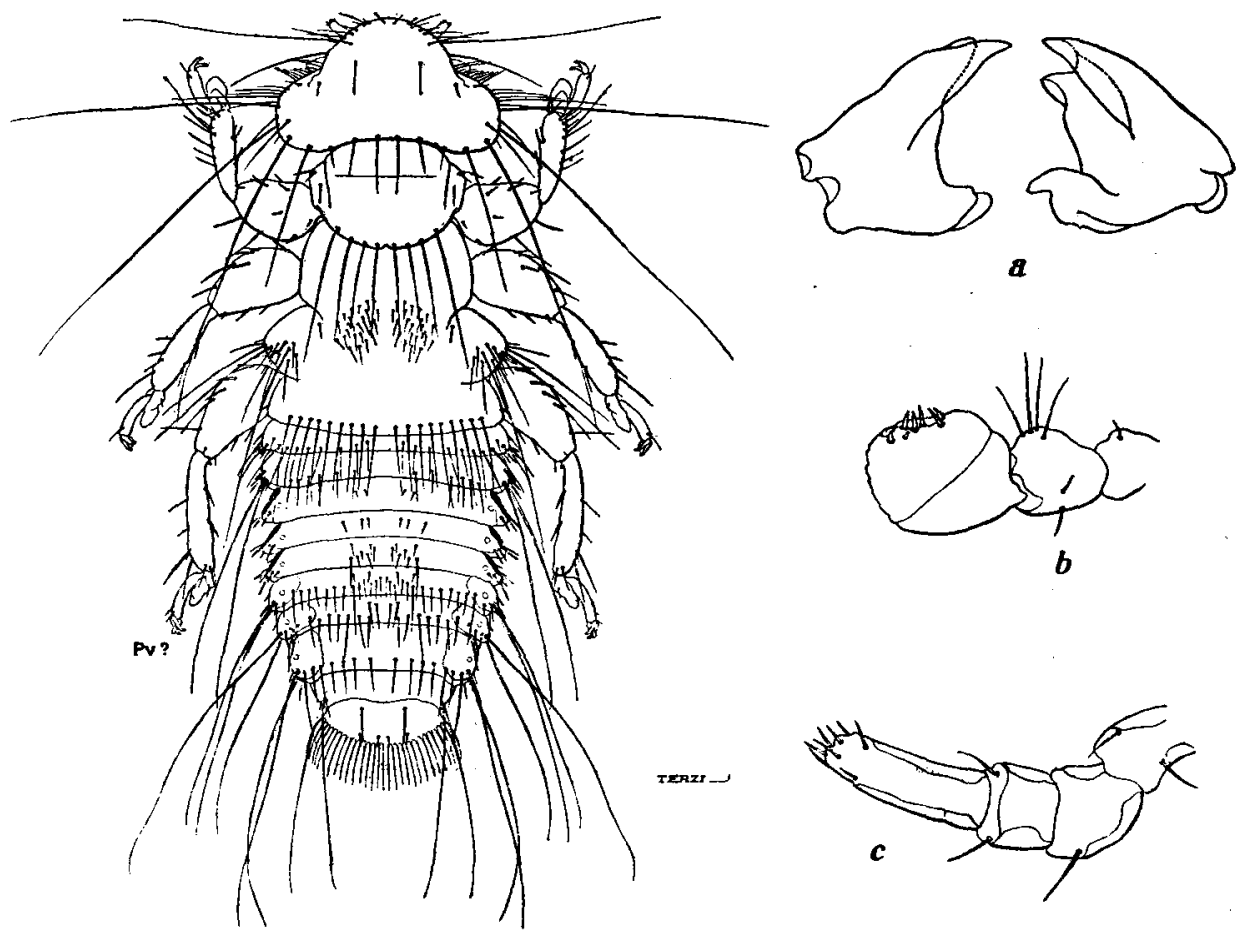

Fig. 7. Menopon robsoni, sp. nov., $q$ : Pv., pulvillus; (a) mandibles; (b) antenna; (c) maxillary palpus.

fringe consisting of about 8 or 9 hairs. Temples with 4 very long hairs, not set in very large alveoli. Along the occipital line two long hairs in the middle, and two shorter ones on each side of this pair further out. A hair on each side on the dorsal surface near the base of the antenna. Thorax: Wings of pronotum with two short spines in front; a third further back well inside the margin. Prosternite with 2 hairs in front. Convex posterior margin of the pronotum with 6 or 7 fairly long hairs. Mesonotum probably bare. Mesosternite with a row of 4 small widelyspaced hairs. Shoulders of metanotum with 3 elongate hairs and about a dozen shorter ones of varying lengths. Hind margin with a row of moderately long hairs. In the middle of the metanotum two patches of small hairs. Posterior half of the 
meta sternite crowded with hairs of medium length. Abdomen : Chaetotaxy a little uncertain owing to lack of material. Tengites with a few minute hairs on the posterior margin ; these are longer on segments 6,7 and 8 . Pleurae of segment 1 with a bunch of small spiny hairs on the ventral surface; those of the other pleurae with smaller and fewer spines in the same position. Pleurite of segment 2 with two long hairs, one very much longer than the other. Pleurites of segments 3,4 and 5 with only minute spines, of segments 6, 7, 8 and 9 with two very elongate hairs. On the sternite of segment $l$ in each anterior outside corner two straight bristles directed forwards. Sternites 3, 4, 5, 6 and 7 with a patch of süall hairs on each side. Sternite 8 with a number of minute scattered hairs over its broad surface. Sternite 9 with a transverse row of rather small hairs.

Mouth-parts.-Mandibles: Inner condyle well developed, in the form of a rounded knob (fig. 7, a). Maxillary palpus (fig. 7, b) : This appendage curves outwards laterally from the mouth-parts to the side of the head, beyond which it projects slightly. This position is brought about by the form of the two basal segments. Isopogometric apparatus : Anterior cornua of oosophageal sclerite with truncate tips. Two posterior projections present. The plate carries a fringe of delicate teeth. The basal pieces are parallel-sided, truncate in front and behind.

Meaurements of MENOPON RớBONI, o, in millimetres.

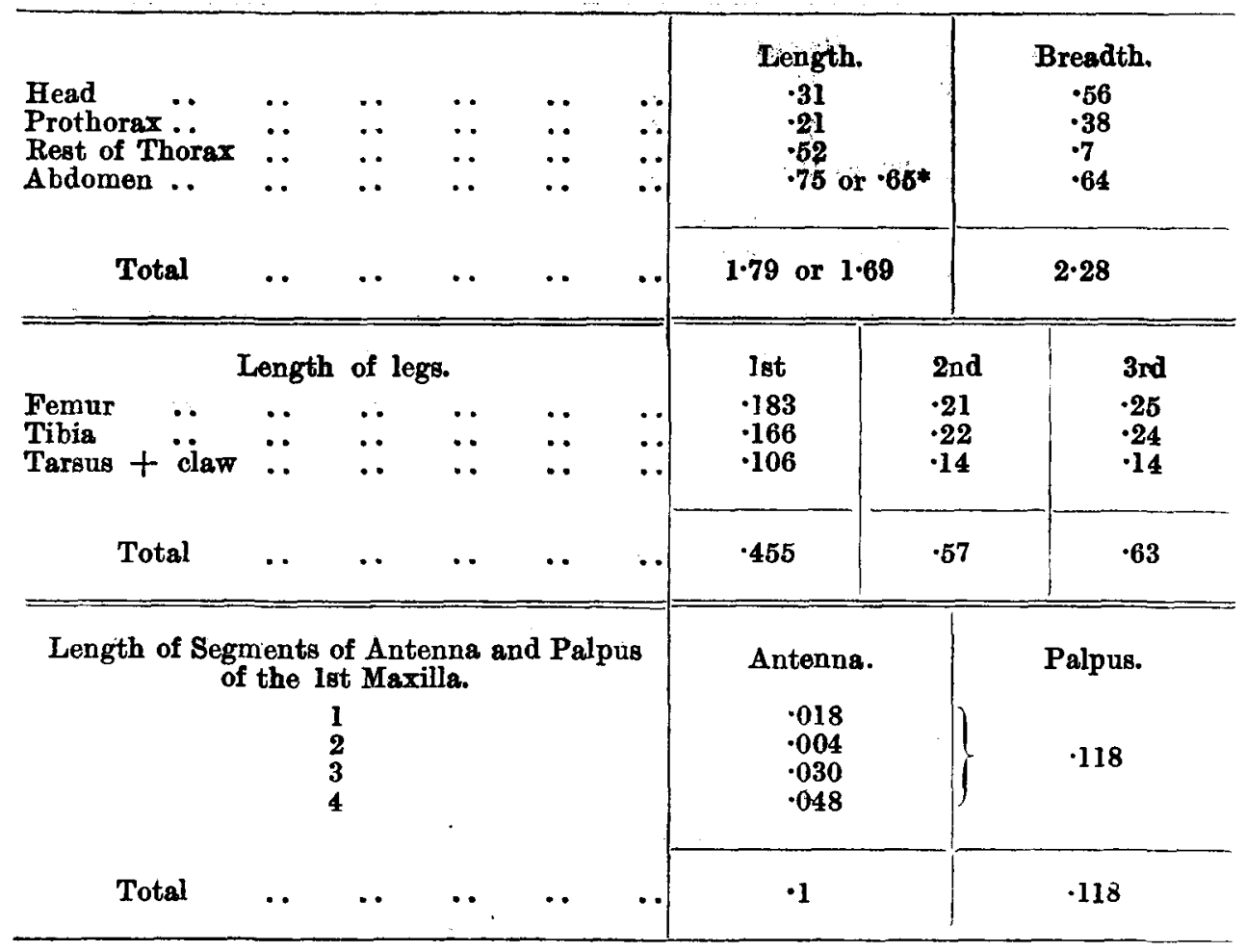

* According one reckons from the real base of the first segment or from the edge of the meta-thoracic overlap. 
Goniocotes watorstoni, sp. nov. (fig. 8).

The specimens on which this description is based were presented to the British Museum in 1913 by the Hon. N. C. Rothschild and were collected by R. N. Atkinson in November 1912, on the penguin, Eudyptula minor, in the Furneaux Islands.

G. waterstoni stands nearest to G. bifasciatus, Piaget (3, p. 47), from Spheniscus demersus, with which, through the kindness of the Rev. James Waterston, I have been able to compare it. The present species differs in its shorter head, in the form of the male genitalia, and its antennae.

External Form, Male.-Head: Preantennary margin perfectly rounded. Antennary sinus large, roofed in dorsally by transparent chitin. Its posterior corner. is produced forwards into an angle with several small hairs on it. Immediately. behind this angular projection at the side of the head is the eye, which carries a short spine. Antenna almost four-segmented, as the fifth segment is very small and partly fused with the fourth. The first segment is the largest, equal in length to half the length of the whole antenna, swollen. Temples with two angles, the rounded anterior one carried outwards so as to make the post-antennal area of the head almost. as broad as the abdomen. The posterior angles are produced backwards on either side of the occiput so as to embrace the prothorax (fig. 8 a). The two occipital apodemes tapering and slightly convergent. Thorax: The prothorax is broad and short, the hind margin of the pronotum convex on the metanotum. The endoskeleton shows, as usual, the two clavicles running upwards and forwards from the prosternal region to the anterior lateral corners. The upper part of each clavicle is slender and narrow, the lower part broadening out. The main difference between the prothoracic endo-skeleton and that in the other species here described is that the clavicles do not descend very appreciably from the anterior corner of the pronotum towards the prosternum but abut against, without actually fusing with, two small rectangular plates lying within the rear part of the prothorax. These two small plates lie above and are apparently connected with two larger plates of irregular outline, representing perhaps the prosternite. These extend below the hind margin of the prosternum and their ends lie between the coxae of the second pair of legs; each receives the inner end of two deep brown strongly chitinised bands or septa which run in along the ventral side between the pro- and meso-metathorax from the sides. Metathorax broader than the prothorax, each side running out into a projection. Abdomen : Segments 8, spiracles 6. Pleurites with their internal free ends rounded. First pleurite narrower from left to right than the others, the external " beak" being very small and partly fused with the next pleurite. Terminal segment extremely convex (as usual in GoNIODIDAE). The genital chamber opens by a semicircular slit upon the dorsal surface.

External Form, Female.-Head: Antennary sinus not so large, its anterior and posterior angles being less pronounced. Antennae small. Segment 1 the largest, but much smaller than segment 1 in the $\delta$. Segment 5 more developed than it is in the $\delta$. Abdomen: Pleurites with the free internal ends truncate; terminal segment narrowest, rounded behind, but not convex as in the $\delta$. Genital opening on the lower side of the segment, situated far forward and in the form of a semicircle with its concavity behind. The actual slit is directed backwards and lies 
between dorsal and ventral lips, whereas in the male the slit is directed dorsally and the lips are anterior and posterior.

Chaetotaxy, Male.-Head: Anterior margin with numerous small minute hairs. Dorsal surface with many scattered minute denticles or short spiny hairs. At the anterior lateral angle, one long bristle, succeeded from behind forwards by a very short one, then a longer one and then another shorter one. Posterior lateral angle with one long bristle. Thorax : Along hind margin of pronotum two long hairs, one on each side. Lateral angles of metanotum with two or three long bristles and three or four short spines. Hind margin of metanotum with a row of bristles, the two outside ones being very long and reaching to the fourth abdominal segment. Abdomen: Many fairly long hairs on the dorsal surface occupying the median area. Pleurites bare, except at the external angles, where there are two fairly long bristles, and except for the hind margin of the last pleurite, which has a row of three or four long bristles. Two bristles on the dorsal surface of the last segment arising just over the base of each parameron, one on each side. On the ventral surface there is a single row of rather fine hairs on each of the first six segments. The first row lies between the hind coxae and consists of only four hairs. The sixth row is very convex, starting on each side on segment 6 and curving forward on to segment 5. Convex terminal margin of last segment with numerous long bristles.

Chaetotaxy, Female--Head: Anterior lateral angles of the post-antennal area each with a small spine-like hair and three other spines still more minute. Abdomen : Hind margin of last segment with six long hairs, three on each side. The lower lip of the genital opening with the sides drawn out into a gonopod-like form, bearing numerous short hairs, which are however longer than the hairs along the central part of the lip.

Mouth-parts (fig. 8, b).-Mandibles : As usual, very powerful and densely chitinous; articulation complex. First maxillae consisting of a single pair of lobes, one on each side of the mouth, without palpi. As in Goniodes tetraonis (13) and in some others, these lobes are thin, flattened and atrophied, lying inside the mouth. In this species the lobes are bare of hairs, setae or hooks. Second maxillae: On the labium are the following structures:-(a) two relatively large columnar lobes with terminal spines, usually called paraglossae; $(b)$ between the paraglossae six hairs, three on each side, the two outside ones on each side carried each on a minute prominence; $(c)$ at the base of each paraglossa, lower down on the labium, a minute lobe, well chitinised, angular, bare, previously described by Shipley (13) in G. tetraonis. The paraglossae perhaps represent the labial palpi and the minute lobes $(8 b, \mathrm{OL})$ the outer lobes. Oesophageal sclerite: The anterior cornu short and concave on the inner margin. Cushion, as usual in the Goniodidat, well developed. A round "blob" of dark chitin is situated in the middle of its anterior margin.

Male Copulatory Apparatus.-The figure (fig. $8 \mathrm{c}$ ) makes it possible to dispense with a great deal of description. The parts are rather complex and closely fitting. The lateral margins alone of the basal plate are strongly chitinised. The paramera are short and broad, broader at the distal than at the proximal end. The endomera lie next within the paramera and, though free distally, are fused with one another higher up ; but still higher up they become free again, the free ends being conspicu- 
ously situated on each side immediately on the inside of the lower part of the lateral margin of the basal plate. Within the endomera is a large, somewhat globular piece, probably consisting of the fused telomera. Distally and ventrally it is drawn out into two sharp processes separated by a deep incision. There is apparently no penis.
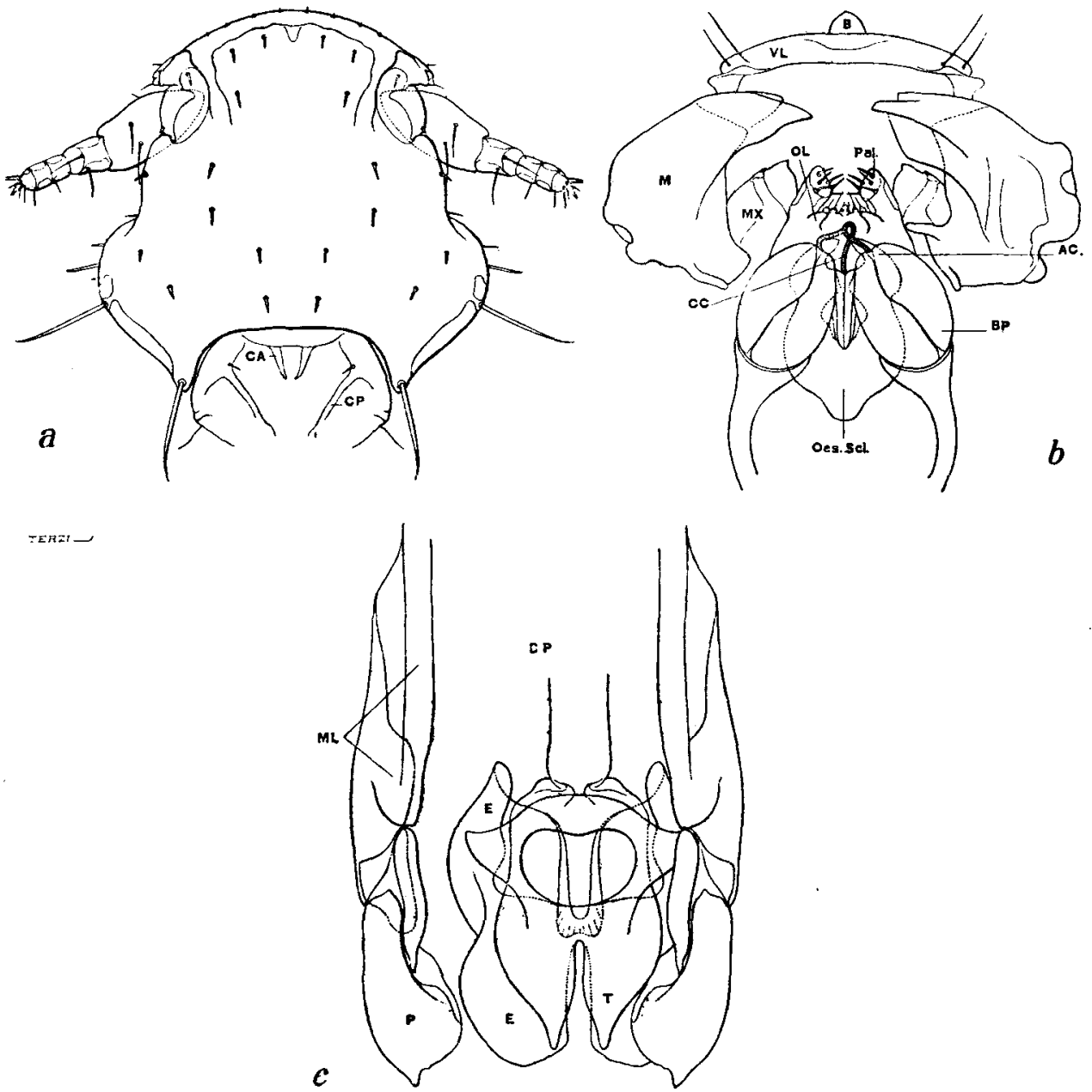

Fig. 8. Goniocotes waterstoni, sp. nov.

(a) Head andiprothorax of $\delta: C A$, cephalic apodeme; CP, clavicle.-(b) Mouth-parts : $B$, tab ; VL, upper lip; $M$, mandible; $M X$, maxillary lobe; $O L$, outer lobe of 2 nd maxilla; Pal., labial palpus; $A C$, anterior cornu of oesophageal sclerite; $C C$, chitinous chord ; BP, basal piece; Oes. Scl., oesophageal sclerite.-(c) Male copulatory apparatus : $B P$, basal plate; $M L$, lateral margin of basal plate; $E$, endomeron; $P$, parameron; $T$, telomeron. 
Measurements of GONIOCOTES WATERSTONI in millimetres.

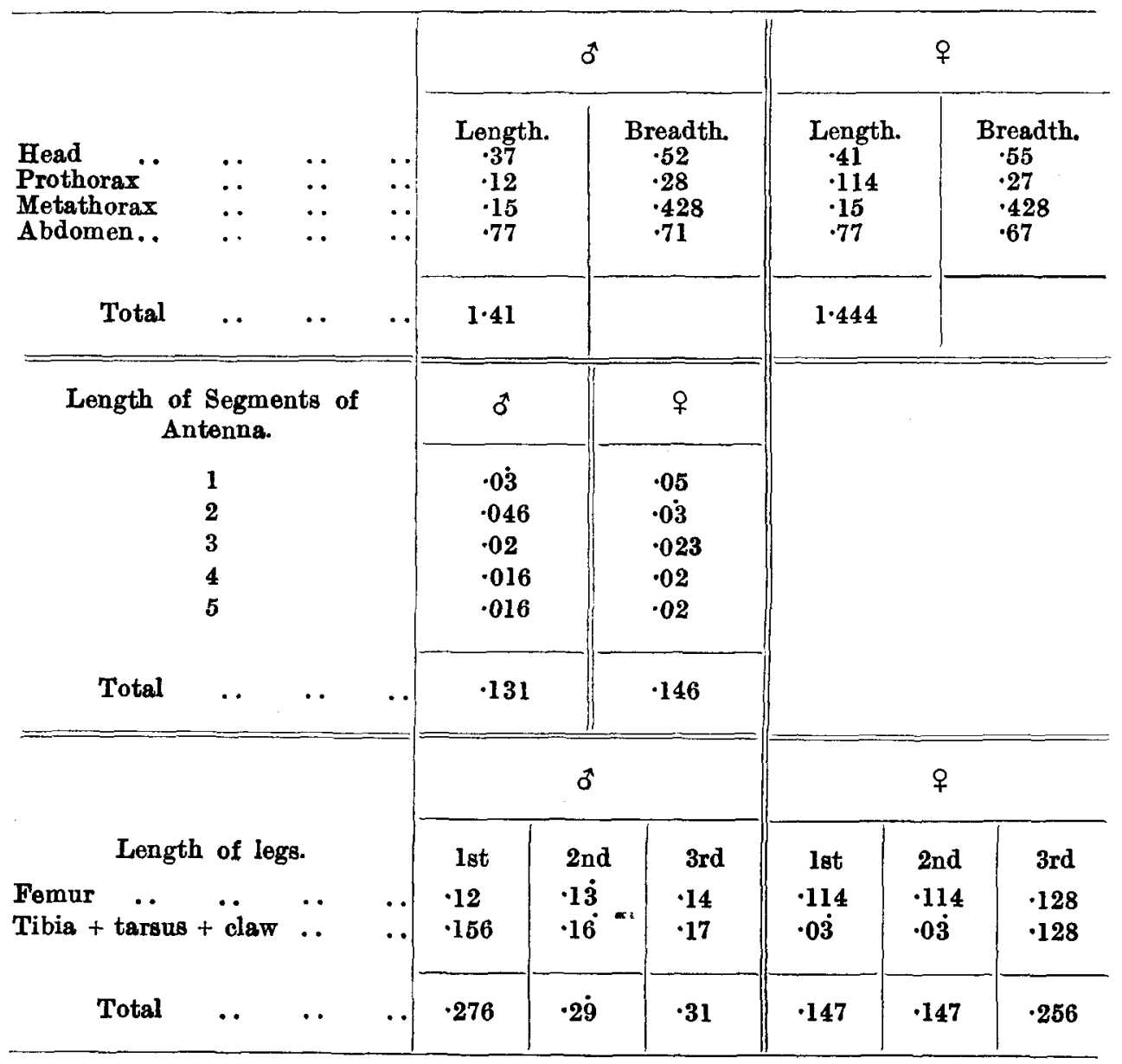

I have to thank the Rev. James Waterston, B.D., B.Sc., of the Imperial Bureau of Entomology, for much kind assistance during the preparation of this paper.

\section{References.}

(1) Lucas, H. Annales de la Société entomologique de France, (2) x, p. 529, pl. xi, fig. 2.

(2) Neumann, L.-G. Archives de Parasitologie, xiii, April 1910, p. 497.

(3) Piaget, E. Les Pediculines, Supplement, 1885, Leide, p. 146.

(4) Rudow. Zeit. f. d. ges. Naturw, xxxiv, p. 167.

(5) Cummings, B. F. (a) Bull. Ent. Res. iv, May, 1913, p. 45. (b) Ann. Mag. Nat. His. (8) xii, Sept. 1913, p. 266.

(6) Mjöberg, E. Arkiv. för Zoologi, vi, 1910, p. 166.

(7) Enderlein, G. Zool. Anz. xxviii, 1905, p. 626. 
(8) Waterston, J. Annals of the South African Museum, x, pt. 9, p. 271.

(9) Kellogg, V. L. and Nakayama, S. Entomological News, xxv, May 1914, p. 193.

(10) Armenante, E. Boll. della Soc. di Naturalisti in Napoli, xxiv (ser. 2, vol. iv), 1910 , p. 76.

(11) Carriker. Univ. Studies, Nebraska, iii, 1903, p. 173.

(12) Kellogg, V. L. Sjöstedt's Zoologische Kilimandjaro-Meru Exp. 1905-6, iii, pts. 15-22, p. 50, pl. vii, fig. 7.

(13) Shipley, A. E. Proc. Zool. Soc. London, 1909, p. 310. 